\title{
Managing Anaesthesia for Abdomino Perineal Resection in a Hypothyroid Patient with Carcinoma Rectum- The Turmoil Unmasked
}

\author{
Author \\ Dr Vaijayanti Nitin Gadre \\ Department of Anaesthesiology, \\ B. J. Government Medical College, Pune. (Maharashtra State), India \\ Mobile number - 9075618317, 9921192739, Email: vaijayantigadre@hotmail.com
}

\begin{abstract}
Thyroid dysfunction in cancer patients can be easily overlooked. The presence of non-specific constitutional symptoms of hypothyroidism can be attributed to those of malignancy. We present a case of carcinoma rectum that was a known hypothyroid since four years and was taking tablet thyroxin 50mcg. Anaesthetic fitness was considered viewing the status of malignancy. She went into profound hypotension which responded readily to thyroxine instillation through Ryle's tube. Thus therapy is not complete unless a diagnosis of the possible precipitating event is made and early treatment for underlying illness is implemented.
\end{abstract}

Keywords: Hypothyroidism, Malignancy, Hypotension.

\section{Introduction}

Hypothyroidism is a commonly occurring problem and easily managed medically. Gastrointestinal manifestations of hypothyroidism are known. From sluggish motility, mild constipation to paralytic ileus and pseudo obstruction has been reported due to decreased metabolic function. ${ }^{[1]}$

Patients with gastrointestinal malignancy also have non- specific symptoms attributed to early malignancy, chemotherapy, radiation or recurrence. Thus, thyroid function needs special surveillance in cases with malignancy.

\section{Case Report}

A 58 years old female with history of bleeding per rectum was referred for abdomino-perineal resection. She was a diagnosed case of cancer rectum from a distant hospital and a known hypothyroid taking tablet thyroxine $50 \mathrm{mcg}$ OD since four years. Her recent thyroid profile showed $\mathrm{T}_{3} 0.897 \mathrm{ng} / \mathrm{ml}(0.8-2), \mathrm{T}_{4} 5.31 \mathrm{mcU} / \mathrm{ml}$ (5.1-14.1), and TSH 7.76mU/1 (0.27-4.20). Clinical examination, blood investigations, ECG and chest $\mathrm{x}$ ray were normal; abdominal and pelvic CT scan reported asymmetrical circumferential wall thickening of rectum and anal canal with polypoid, heterogeneous, hypodense mass lesion involving posterior and right lateral wall of rectum. It was $5.6 \mathrm{~cm}$ long and $19 \mathrm{~mm}$ at maximum thickness causing intra-luminal narrowing and dilatation of proximal sigmoid colon. Fat planes between this lesion and lower third of vagina appeared indistinct. On posterior 
contrast study there was heterogeneous enhancement (CT attenuation value 58-71 HU). There were multiple enhancing perilesional, pararectal, internal iliac and mesenteric group of lymph nodes. A well-defined hyper dense focus was present over the head of femur.

Early surgical intervention was dictated by the state of malignancy without waiting for adequate preoperative thyroid control. Patient received combined spinal epidural anesthesia using $3 \mathrm{ml}$ of $0.5 \%$ bupivacaine with $22 \mathrm{mcg}$ clonidine additive. Skin incision was infra umbilical; peritoneal, liver, spleen and small bowel metastases were negative. Sigmoid was mobilized dissecting dorsally in lithotomy position and resected $10 \mathrm{~cm}$ proximal to growth, involving the growth and anal canal. The specimen was delivered through perineum and end colostomy was performed.

Patient tolerated the procedure well (blood pressure 96-110mmHg) for initial two hours; there was ongoing blood loss $(1750 \mathrm{ml})$ and continuous ooze. Volume replacement attempted using crystalloids, colloids and blood and blood products in pre-determined dose and infusion dopamine $\quad(0.1-0.3 \mathrm{mcg} / \mathrm{kg} / \mathrm{min}) \quad$ started for circulatory support. General anaesthesia was administered. Hypotension (BP-60/40mmHg, CVP-0-1 $\mathrm{cmH}_{2} \mathrm{O}$ ) persisted; ECG showed 140160beats/min rate and rhythm was regular.

Infusion noradrenaline $(0.05-0.1 \mathrm{mcg} / \mathrm{kg} / \mathrm{min})$ and dobutamine $(2.5-5 \mathrm{mcg} / \mathrm{kg} / \mathrm{min})$ showed no favourable outcome. She remained hypotensive for one hour even after haemostasis and complete surgical closure was accomplished. Tablet thyroxine $150 \mathrm{mcg}$ dissolved in $10 \mathrm{ml}$ saline was instilled through Ryle's tube. Blood pressure restored to $80-90 \mathrm{mmHg}$ systolic within 20 minutes and CVP gradually rose to $10 \mathrm{~cm}$; patient was shifted to intensive care and electively ventilated for 24 hours. Ventilator support and vasopressor weaned off after stabilization of CVP $12 \mathrm{cmH}_{2} \mathrm{O}$, blood pressure $100 \mathrm{mmHg}$ and urine output $1-1.5 \mathrm{ml} / \mathrm{kg} /$ hour. Tablet thyroxine $150 \mathrm{mcg}$ dose continued daily. She was extubated on third postoperative day and discharged from ICU.
Uneventful recovery until safe discharge to home was monitored daily in ward for two weeks. Normal blood levels of TSH were documented after one month.

\section{Discussion}

Subclinical Hypothyroidism is the diagnosis based on findings of normal levels of $\mathrm{T}_{3}$ and $\mathrm{T}_{4}$ with high TSH values. This is commonly found in elderly females with non-specific symptoms like easy fatigability, lethargy and constipation. ${ }^{[2]}$ Treatment of such cases is warranted with single daily dose of thyroxine and monitoring of blood levels over several months. However early surgical intervention was required in our case because of malignancy.

Also, the treatment of subclinical hypothyroidism is debated and is advisable if blood level of TSH is above $10 \mathrm{mU} / \mathrm{l}^{[3]}$

Hormonal effects on gastrointestinal tract are due to synergistic effects of thyroid hormone with catecholamine. Chloride flux causes diarrhoea in hyperthyroidism whereas in hypothyroidism accumulation of glycosaminoglycans causes interstitial oedema of skin, heart, skeletal and smooth muscles. Thyroid malignancies are associated with colorectal cancer. ${ }^{[4]}$

This patient had intra-operative precipitate hypotension and blood loss. Hematologic manifestations of hypothyroidism include a decrease in factor VIII activity, prolonged partial thromboplastin time, and acquired von Willebrand disease. Tendency to thrombosis is reported with mild hypothyroidism. Severe hypothyroidism is associated with higher risk of bleeding and coagulopathy. Micro or macrocytic anaemia secondary to haemorrhage and vitamin $\mathrm{B}_{12}$ deficiency worsens neurological state. ${ }^{[5]}$

Subclinical hypothyroidism impairs myocardial contractility and 30-50\% decreased cardiac output due to deposition of glycosaminoglycans in the myocardial tissues. There is prolongation of preejection period, subnormal systolic and diastolic function with reduced $\mathrm{LV}$ ejection time. ${ }^{[6]}$ 
Furthermore, deficiency of thyroid hormones causes an increase in peripheral vascular resistance resulting in increased cardiac afterload, leading to a decreased pulse pressure via an increase in diastolic pressure and a decrease in systolic blood pressure. $^{[7]}$ Even though catecholamine levels are increased in these patients, hypothyroid patients have a predisposition to develop hypotension under anaesthesia, likely due to downregulation of $\beta$ adrenergic receptors. ${ }^{[8]}$

Weinberg et al [9] analysed the outcome of anaesthesia and surgery in 59 hypothyroid patients compared with 50 euthyroid patients. Duration of surgery or anaesthesia, lowest temperature and blood pressure recorded during surgery, need for vasopressors, time to extubation, fluid and electrolyte imbalances, incidence of arrhythmias, pulmonary or myocardial infarction, sepsis, need for postoperative respiratory assistance, bleeding complications, or time to hospital discharge were comparable. Analysis of groups of patients divided based on their thyroxine levels (thyroxine level $<1.0 \mu \mathrm{g} / \mathrm{dL}, 1.0$ to $<3.0 \mu \mathrm{g} / \mathrm{dL}$, and $\geqslant 3.0$ $\mu \mathrm{g} / \mathrm{dL}$ ) revealed no differences in outcomes. The authors concluded that in mild to moderate hypothyroidism, there is no evidence to justify postponing surgery that is needed, but in severe hypothyroidism, there is insufficient evidence to make a recommendation. ${ }^{[9]}$ Treatment of this condition with $\mathrm{T}_{4}$ is controversial for levels that can be physiologically effective carry risk of fatal tachyarrhythmia and myocardial infarction. $\mathrm{T}_{3}$ has quicker onset of action, effects on temperature and oxygen consumption. It crosses the blood-brain barrier rapidly, particularly improving profound neurological symptoms of hypothyroidism. ${ }^{[10]}$

The pathophysiologic changes associated with hypothyroidism are generally reversible with replacement of thyroid hormone. Thus, rather than face the risk of acute decompensation, it is preferable to postpone elective surgery until adequate treatment with thyroid hormone has achieved euthyroidism. A full dose of levothyroxine is usually $1.6 \mu \mathrm{g} / \mathrm{kg} / \mathrm{day}$; if oral medications cannot be given postoperatively, the dose may be administered enterally. After 5 days, intravenous (IV) levothyroxine should be administered at a dose between $60 \%$ and $80 \%$ of the oral dose.

\section{Conclusion}

The diagnosis of hypothyroidism should always be suspected in cancer patients and the treatment is also pertinent to avoid complications. The goal of perioperative therapy is to attempt to normalize hormone levels prior to surgical intervention whenever possible and, when that is not feasible, other measures that will maximize hemodynamic stability and prevent decompensation should be adopted.

\section{References}

1. Bassotti G, Pagliacci MC, Nicoletti I, Pelli MA, Morelli A. Intestinal pseudoobstruction secondary to hypothyroidism. Importance of small bowel manometry. J ClinGastroenterol 1992; 14:56-58.

2. Cooper DS. Subclinical Hypothyroidism. N Engl J Med 2001; 345: 260-265.

3. Gillet $M$ Subclinical hypothyroidism: subclinical thyroid disease: scientific review and guidelines for diagnosis and management. JAMA 2004; 291: 228-238.

4. Christina Maser, ArnbjornToset, Sanziana Roman. Gastrointestinal manifestations of endocrine disease. World J Gastroenterol 2006; 12(20): 3174-3179.

5. Joanna Klube-Gwiezdzinska, Leonard Wartofsky. Thyroid Emergencies. Med Clin N Am 2012; 96: 385-403.

6. Biondi B, Palmieri EA, Lombardi G, Fazio S. Effects of Subclinical Thyroid Dysfunction on Heart. Annals of Internal Medicine 2002; 137: 904-914.

7. Stahatos N, Wartofsky L. Perioperative management of patients with hypothyroidism. Endocrinol Metab Clin North Am. 2003; 32:503-518. 
8. Bilezikian JP, Loeb JN. The influence of hyperthyroidism and hypothyroidism on $\alpha$ and $\beta$-adrenergic receptor systems and adrenergic responsiveness. Endocr Rev. 1983;4:378-388.

9. Weinberg AD, Brennan MD, Gorman CA, Marsh HM, O'Fallon WM. Outcome of anesthesia and surgery in hypothyroid patients. Arch Intern Med. 1983; 143:893897.

10. Chernow B, Burman KD, Johnson DL, McGuire RA, O’Brian, John T, Wartofsky, Leonard, Georges, Leon P. T3 may be a better agent than $\mathrm{T} 4$ in the critically ill hypothyroid patient: Evaluation of transport across the blood-brain barrier in a primate model. Critical Care Medicine 1983; 11(2):99-104. 